\title{
Gestão da biblioteca escolar: metodologias, enfoques e aplicação de ferramentas de gestão e serviços de biblioteca
}

\author{
Ariel Behr \\ Bacharel em ciências contábeis - UFRGS. Tutor do Curso de \\ Especialização em Bibliotecas Escolares e Acessibilidade (Ebea). \\ FABICO/UFRGS. \\ E-mail: arielbe@terra.com.br
}

Eliane Lourdes da Silva Moro

Doutoranda e mestre em educação - PPGEDU/UFRGS

E-mail: eliane_moro@yahoo.com.br

Lizandra Brasil Estabel

Doutora em informática na educação - PGIE/UFRGS

E-mail: liz.estabel@gmail.com

\section{Resumo}

Este artigo apresenta a gestão da biblioteca escolar com enfoque na aplicação de ferramentas de gestão para avaliação da qualidade dos serviços oferecidos. Aborda as questões de qualidade e de administração como gestão garantindo aos serviços as características das expectativas e necessidades dos usuários da biblioteca escolar. O bibliotecário, como gestor dos serviços prestados na tomada de decisão, tem competência para utilizar as ferramentas que auxiliam a avaliar seus serviços, como brainstorming, diagrama de causa e efeito, diagrama de Pareto, histograma, matriz de priorização GUT, ciclo PDCA, fluxograma e $5 \mathrm{~W} 2 \mathrm{H}$. Apresenta ainda algumas situações de problemas e dificuldades no âmbito da biblioteca escolar exemplificadas na utilização das ferramentas e a aplicação da junção de três ferramentas (fluxograma, PDCA e 5W2H) para avaliação dos serviços.

\section{Palavras-chave}

Biblioteca escolar. Gestão. Ferramentas de gestão.

\section{School library management: methodologies, focus and application of management tools and library services}

\section{Abstract \\ This article focuses the school library management with reference to the application of management tools for assessment of the quality of services offered. Issues of quality and administration are approached, as for instance, assurance of services expected and needed by the users of the school library. It is the librarian's duty, as a manager of the services rendered for decision making, to utilize the tools which help him to assess the services and some of the tools as follows: brainstorming, cause and effect diagram, Pareto chart, histogram, GUT priority matrix, PDCA cycle, flowchart and 5W2H. Some situations of problems and difficulties in the context of the school library are also presented as the joint utilization of tools and application (flowchart, PDCA cycle and 5W2H) for assessment of the services.}

\section{Keywords}

School library. Management. Management tools.

\section{INTRODUÇÃO}

Na sociedade da informação e do conhecimento, a biblioteca escolar ocupa um espaço significativo no que concerne a suas metodologias, enfoques e aplicação de ferramentas de gestão e serviços. Nas diretrizes da biblioteca no sistema educacional em nível internacional, nacional e regional, a gestão em serviço de bibliotecas escolares deve priorizar a aprendizagem em todo o processo de desenvolvimento humano, além do acesso e uso da informação. Segundo o Manifesto Ifla/Unesco em Bibliotecas Escolares, essa apropriação deve desenvolver a imaginação e preparar os cidadãos para uma vivência responsável, possibilitando o pensamento crítico e o efetivo acesso à informação em todos os formatos e meios.

Alguns autores, ao tratarem sobre gestão, na área biblioteconômica, apresentam a visão empresarial em que o bibliotecário exerce a função de administrador, o usuário é o cliente e o serviço oferecido é o produto. A biblioteca escolar se caracteriza como função pedagógica e abrange ampla "clientela" e de diversos níveis de escolaridade, pois seus usuários pertencem à faixa etária dos dois aos oitenta anos, desde a educação infantil ao pós-médio, incluindo a educação de jovens e adultos, o corpo docente, funcionários e comunidade escolar. O bibliotecário tem a função de gestor e de educador, buscando a oferta de serviços, através da avaliação no uso de ferramentas de gestão, e qualidade, propiciando o acesso e o uso da informação para todos.

Este artigo aborda metodologias e ferramentas de gestão que, com certeza, contribuirão para os resultados eficientes e eficazes dos serviços oferecidos com enfoque na biblioteca escolar, no bibliotecário, nos serviços de qualidade e no usuário. A gestão preconiza a qualidade de serviços com foco na eficiência e na eficácia, buscando a rapidez e o resultado satisfatório que atenda às necessidades de informação dos usuários.

\section{TEORIA DA QUALIDADE}

Provavelmente o assunto "qualidade" não é novidade para nenhum de nós. O termo é muito utilizado em 
diversos setores de negócio, e isso contribuiu para sua difusão eficaz. Na verdade, o conceito de qualidade é intuitivo, pois sempre dizemos que aquilo que nos agrada é algo de "qualidade". Essa grande popularidade do assunto, por vezes, nos faz acreditar que qualquer um cria uma teoria, põe seu nome nela e sai publicando livros, mas não é bem assim.

A qualidade tem esse nome não por acaso, mas sim por seu primeiro ideal, o de que produtos industrializados tivessem uma constância em sua fabricação. Desde então se passou a associar o nome a um padrão, e é justamente este padrão que mantém a ideologia viva. Dizer que simplesmente um produto é fabricado sempre da mesma maneira não quer dizer que ele será bom para todos, pois a relação de bom e ruim envolve muita subjetividade. Então a qualidade se propõe a dizer que o produto tem sempre as mesmas características e atende às mesmas necessidades.

Da evolução deste conceito nasceram diversas teorias, metodologias, escolas e institutos, todos voltados a um mesmo norte. Uma das principais comprovações disso são as certificações ISO (International Organization for Standardization), que têm como objetivo garantir que um produto possui determinadas características, e em cada número de certificado (ISO 9000, ISO 14000, entre outros) tais características são descritas. Segundo Hertis Information and Research (1993), apud Vergueiro $(2002)^{1}$, esta instituição internacionalmente reconhecida surgiu motivada pelas indústrias de armamento norteamericanas e inglesas, que precisavam de produtos com características especificadas para eles, pois de nada nos serviria ter uma bola de canhão fabricada com um diâmetro maior do que o do cano pelo qual será disparada. E, tão logo ficou conhecida, a norma ISO passou a ser requisito para qualquer negociação comercial.

Vergueiro (2002) afirma que, mesmo que existam diversos nomes para as teorias da qualidade, todos devem sua gênese à evolução do pensamento teórico da ciência administrativa, que iniciou a busca pelo conhecimento do ambiente de tomada de decisão, e, realmente, a qualidade e a ciência administrativa são muito próximas, não só nos conceitos, mas em seu campo de atuação também.

${ }^{1}$ HERTIS INFORMATION AND RESEARCH. Total Quality Management: the information business: key issue 92 . Hatfield: University of Hertfordshire, 1993, apud VERGUEIRO, Valdomiro. Qualidade...
Chegamos assim ao ponto de decisão: qualidade ou administração? Ficaremos com as duas. Passaremos a chamar essa mistura de gestão pela qualidade, ou seja, uma maneira de organização da biblioteca na qual visamos garantir aos serviços as características que estão na expectativa dos usuários.

Para alcançarmos os objetivos propostos e expressar nosso pensamento é importante termos claro que, como o nome diz, a gestão pela qualidade é um método de gestão, ou seja, uma maneira de administrar calcada em alguns princípios. Para nos auxiliar nesta reflexão, buscamos algumas técnicas de qualidade, que podem ser utilizadas, tais como 5S, just in time, gerência de projetos, entre outras e, ainda, algumas ferramentas da qualidade, que serão apresentadas posteriormente e têm como objetivo auxiliar na aplicação dos conceitos da qualidade de maneira eficaz.

Podemos dizer que o tema qualidade é algo com uma dimensão abrangente e que pode ser aplicado onde exista gestão. Ficaremos, então, restritos a apresentar idéias que possam ser utilizadas diretamente na biblioteca e nos serviços de informação para não perdermos o escopo do estudo.

\section{TEORIA DE SISTEMAS}

A teoria de sistemas foi proposta nos anos 50 pelo biólogo Ludwig von Bertalanffy (1975) e tem como objetivo analisar conjuntos, independentemente de sua formação e configuração. Essa teoria pretende abordar todos os fatores que envolvem determinada entidade complexa e criar modelos para sua descrição.

As premissas desta metodologia de análise dizem que um sistema é um conjunto de partes interdependentes, ou seja, que travam uma relação de dependência entre si, e formam um todo com funções e objetivos comuns. Nesta direção, qualquer soma de partes, com um objetivo comum, pode ser considerada um sistema.

Usualmente os sistemas são classificados sob dois enfoques, que podem ser simplesmente definidos como abertos e fechados. Basicamente, os sistemas fechados são os que não interagem com o meio em que estão inseridos, e os sistemas abertos são aqueles em que existe uma interação do sistema com o ambiente em que está envolto. Essa interação já nos remete a uma simples visualização do que seria um sistema.

No momento em que aceitamos que existe uma troca com o ambiente, concebemos que o sistema tem entrada, 
por onde recebe estímulos de seu ambiente, e saída, por onde entrega seu produto ao ambiente. Este processo é chamado de realimentação, e estas podem ser positivas e negativas para o sistema. No momento em que o sistema recebe uma informação, transforma segundo suas características e dá saída na mesma, dizemos que o sistema processou a informação (figura 1).

Assim, cada vez que uma informação é processada pelo sistema, o ambiente recebe uma informação modificada com as características do sistema, e, sendo assim, o ambiente vai se renovando e tende a se regular por conta das diversas características de todos os sistemas que o formam.

As particularidades de cada sistema, ao serem lançadas ao ambiente, têm a capacidade de influenciar positiva ou negativamente os demais sistemas deste. Assim, de acordo com Bertalanffy (1975), a evolução é ininterrupta enquanto os sistemas se auto-regulam.

Poderíamos desenvolver discussões diversas sobre o tema, mas o objetivo da apresentação deste assunto é simples: verificarmos que todo sistema tem uma entrada, um processo e uma saída.

\section{FERRAMENTAS DE GESTÃO OU FERRAMENTAS DA QUALIDADE}

As ferramentas da qualidade são instrumentos para identificar oportunidades de melhoria e auxiliar na mensuração e apresentação de resultados, visando ao apoio à tomada de decisão por parte do gestor do processo. Por exemplo, uma biblioteca escolar precisa medir seus resultados de consulta e de empréstimo de acervo de uma determinada área do conhecimento, para poder definir a necessidade de novas aquisições, de política de seleção e de crescimento do acervo naquela área específica. $\bigcirc$ gestor de um serviço, da mesma maneira, precisa mensurar o uso do acervo através da procura, da consulta e do empréstimo no atendimento da necessidade e da satisfação dos usuários, uma vez que isso determinará a eficiência e a qualidade dos serviços oferecidos.

Somente de posse dos dados de sua atividade, o bibliotecário poderá comparar os serviços prestados com seus próprios processos na busca da excelência dos mesmos. As ferramentas, então, auxiliam o bibliotecário a planejar, organizar e avaliar seus serviços e apresentar resultados que indiquem qualidade nos serviços prestados. Para auxiliar no processo de gestão e serviços de qualidade, selecionamos algumas ferramentas e
FIGURA 1

Sistema Aberto

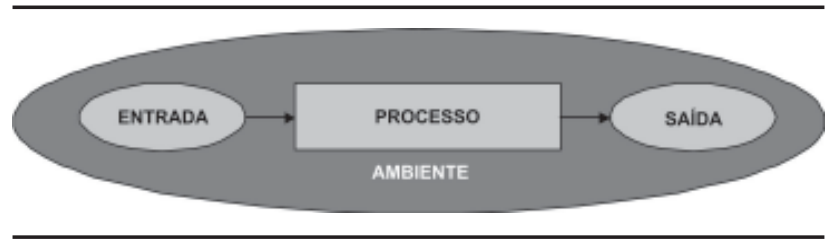

Fonte: Bertalanffy (1975).

exemplos que, por sua simplicidade e objetividade, podem servir ao bibliotecário na gestão da biblioteca escolar.

\section{Brainstorming}

O brainstorming é uma ferramenta simples que pode ser utilizada em qualquer situação. Podemos dizer que é uma ferramenta para o surgimento de idéias ou para evidenciação de problemas. A técnica surgiu na década de 30 com o publicitário Alex Osborn e tinha o propósito de criar um ambiente onde "chovessem idéias", daí surgindo seu nome, que também é muito utilizado em nosso idioma, como "tempestade ou explosão de idéias".

Esta técnica deve ser utilizada em grupo e, por suas características, desenvolve no mesmo um sentimento de comprometimento com a causa analisada, responsabilidade compartilhada e é muito útil quando se deseja maior envolvimento do grupo.

O brainstorming deve priorizar a quantidade e não a qualidade das idéias e pode ser conduzido de duas maneiras. Uma estrutura na qual são feitas rodadas e cada participante deve dar uma idéia ou dizer "passo" ao chegar a sua vez; assim quando só restar um participante dando idéias, encerra-se a técnica e outra forma não-estruturada, na qual o grupo se reúne e livremente expõe suas idéias.

É interessante verificarmos mais alguns aspectos sobre essa ferramenta, tais como:

a. Ambiente: é importante que seja desenvolvido em um ambiente confortável para que os participantes dêem suas contribuições sem se inibirem perante o grupo. A espontaneidade do grupo é um fator preponderante para que as idéias sejam criativas e variadas.

b. Grupo: quanto mais distinto for o grupo, mais ricas serão as idéias colhidas. Mas é fundamental que todos os envolvidos estejam focados para o alcance de um resultado, só assim existirão objetividade e comprometimento. 
c. Condução: a presença de um condutor dos trabalhos é importante para que a técnica seja desenvolvida com objetividade e para que se assegurem a espontaneidade e a originalidade das idéias. As palavras ditas não devem ser interpretadas nem alteradas pelo condutor, e este também deve evitar críticas às idéias para que nenhum participante fique inibido.

Podemos então seguir a seguinte seqüência para realizar o brainstorming:

a. introdução: onde se apresenta a questão a ser pensada;

b. criação de idéias: a tempestade propriamente dita;

c. revisão: momento em que se listam as idéias e se retira qualquer dúvida sobre o entendimento das palavras;

d. seleção: momento em que se hierarquizam as palavras e se eliminam as que, em consenso, não sejam adequadas.

e. ordenação: onde é feita a priorização das idéias. Para este momento também podemos utilizar outras técnicas auxiliares que serão explicadas a seguir, como, por exemplo, a matriz GUT.
Diagrama de causa e efeito (espinha de peixe / diagrama de Ishikawa)

O objetivo da ferramenta está em evidenciar e organizar as causas de determinado "problema". Poderíamos agregar esta com o brainstorming para termos um resultado ainda mais rico, mas por si só esse diagrama já auxilia bastante o gestor.

Podemos utilizá-lo sempre que quisermos saber as causas primárias e secundárias de um efeito (positivo ou negativo) do nosso negócio. Com o diagrama pronto, a visão do negócio será ampliada e a análise de ambiente será facilitada e, por conseqüência, as propostas de melhorias também.

Para construirmos um diagrama de causa e efeito primeiramente definimos o problema, ou efeito, a ser analisado. Em seguida, pode ser feito um breve brainstorming para evidenciarmos a maior quantidade de causas que auxiliem a criar o problema. Simplesmente se pergunte o porquê de aquele problema estar acontecendo. Usualmente alguns autores citam o $4 \mathrm{M}$ para ajudar neste processo, ou seja, vislumbrar os fatores máquina, mão-de-obra, método e materiais agindo sobre seu problema.

Para que possamos praticar a montagem do diagrama, pensemos em um problema com acessibilidade em uma biblioteca (figura 2).

FIGURA 2

Diagrama de causa e efeito

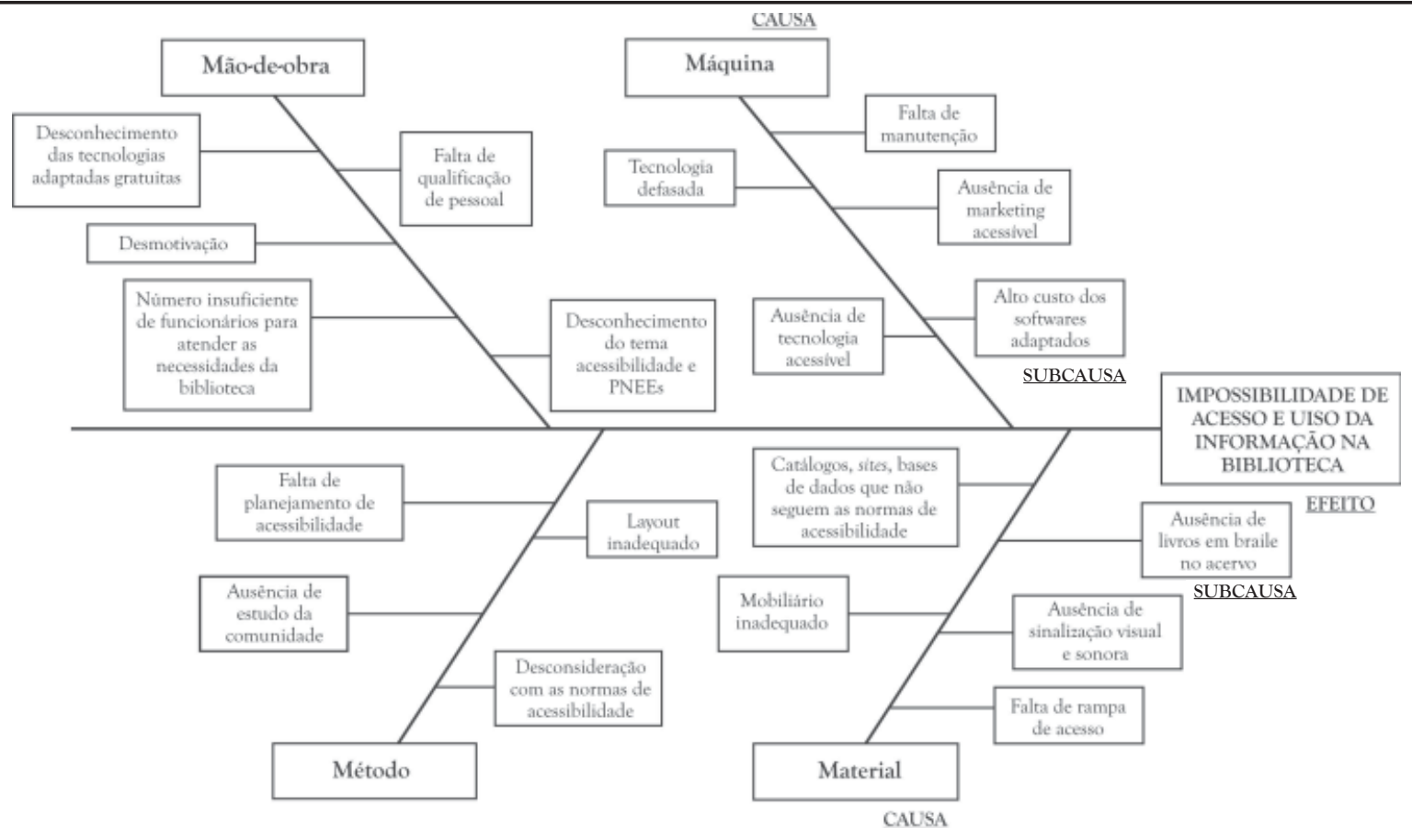




\section{Diagrama de Pareto}

O diagrama de Pareto nada mais é do que colocarmos dados coletados em nossa atividade em um gráfico de barras verticais. Para coletar dados, podemos fazer um acompanhamento das nossas atitudes e dos nossos usuários, podemos fazer pesquisas de opinião, colher idéias em uma caixa de sugestões e por aí afora. De posse dos dados, inseri-los no gráfico, que geralmente tem no eixo vertical a "quantidade de repetições de determinada situação ou problema" e no eixo horizontal o "tipo de problemas".

Essa ferramenta auxilia o gestor a identificar o local onde existe o maior número de ocorrências de situações problemáticas e priorizar suas ações. Como exemplo desta ferramenta, apresentamos Vergueiro (2002, p. 56) (figura 3).

\section{Histograma ou diagrama de freqüência}

O histograma é uma ferramenta com aparência próxima ao diagrama de Pareto, mas envolve a medição de dados (tempo, temperatura, altura, entre outros) e mostra sua distribuição conforme a freqüência em que aparecem. Esta técnica torna-se interessante, pois informa visualmente a concentração dos dados verificados, e a análise de suas variações ao longo do tempo é muito rica.

A montagem do histograma é simples e nos remete a alguns conceitos estatísticos, como podemos verificar observando a seqüência a seguir:

a. saber o tamanho da população analisada, ou seja, saber quantos valores coletamos;

b. determinar a amplitude da população, na prática, saber a diferença entre o maior e o menor resultado da população;

c. dividir a amplitude em classes ou categorias. Quanto maior o número de classes, mais pontual será a análise dos dados, porém um número maior do que 12 já dificulta esta análise;

d. determinar o tamanho e o limite das classes, ou seja, um valor inicial e um valor determinado para sabermos como a população se distribuirá;

e. construir uma tabela da freqüência em que os dados aparecem;

f. construir o histograma com base na tabela de freqüência.
FIGURA 3

Diagrama de Pareto

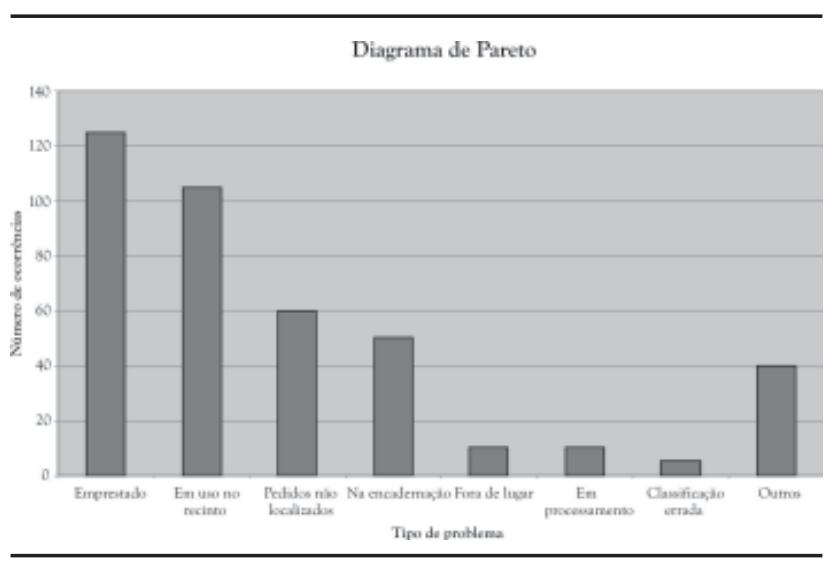

É importante salientar que no histograma aparece toda a população analisada e não só sua região de concentração. As figuras formadas pelo histograma podem ser concentradas no meio do gráfico ou em suas pontas, e cabe a quem estiver analisando verificar se isso é um comportamento normal ou não. A seguir, temos um exemplo da aplicação do histograma onde veremos a distribuição do tempo de atendimento, em minutos, de um serviço de atendimento ao usuário, por exemplo.

\begin{tabular}{|c|c|c|c|c|c|c|c|c|c|}
\hline 7,13 & 7,04 & 4,24 & 9,21 & 9,39 & 1,24 & 7,42 & 1,58 & 7,07 & 5,19 \\
\hline 4,51 & 4,15 & 2,36 & 4,53 & 6,04 & 6,30 & 6,13 & 4,50 & 4,38 & 1,15 \\
\hline 5,37 & 5,13 & 4,41 & 6,44 & 2,29 & 4,18 & 8,25 & 7,20 & 5,10 & 8,32 \\
\hline 6,16 & 6,35 & 1,37 & 7,18 & 4,38 & 1,46 & 2,22 & 6,41 & 6,22 & 4,35 \\
\hline 6,41 & 8,32 & 5,42 & 4,36 & 7,09 & 6,45 & 4,14 & 5,71 & 3,21 & 1,40 \\
\hline 8,21 & 6,08 & 7,50 & 4,22 & 6,24 & 7,46 & 5,03 & 3,23 & 4,39 & 3,45 \\
\hline 4,02 & 8,52 & 4,27 & 2,49 & 8,04 & 1,11 & 5,29 & 9,36 & 7,10 & 6,03 \\
\hline 5,36 & 5,20 & 9,18 & 4,28 & 6,45 & 7,51 & 4,19 & 4,77 & 6,51 & 9,11 \\
\hline 3,65 & 8,22 & 9,28 & 9,32 & 5,38 & 7,05 & 4,18 & 3,43 & 1,19 & 5,11 \\
\hline
\end{tabular}

\section{PASSO 1}

Total de valores coletados $=100$

\section{PASSO 2}

Amplitude = 9,39 - 1,11 = 8,29

\section{PASSO 3}

Definimos que serão 10 classes apresentadas de 1 em 1 .

\section{PASSO 4}

Limite $=$ Menor valor arredondado + intervalo das classes $=1+1=2$ 
PASSO 5

\begin{tabular}{c|c|c|c}
\hline Classe & Limite & Ponto Médio & Freqüência \\
\hline 1 & $0-1$ & 0,5 & 0 \\
\hline 2 & $1-2$ & 1,5 & 8 \\
\hline 3 & $2-3$ & 2,5 & 4 \\
\hline 4 & $3-4$ & 3,5 & 7 \\
\hline 5 & $4-5$ & 4,5 & 24 \\
\hline 6 & $5-6$ & 5,5 & 15 \\
\hline 7 & $6-7$ & 6,5 & 16 \\
\hline 8 & $7-8$ & 7,5 & 12 \\
\hline 9 & $8-9$ & 8,5 & 7 \\
\hline 10 & $9-10$ & 9,5 & 7 \\
\hline
\end{tabular}

FIGURA 4

\section{Histograma}

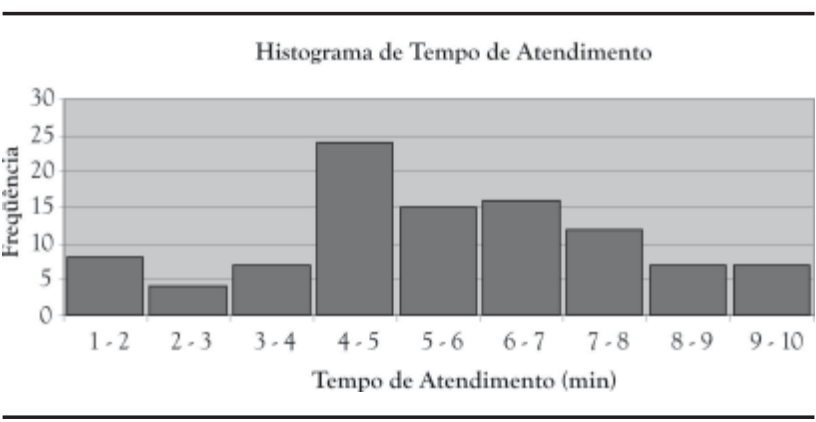

\section{Matriz de priorização GUT}

Essa matriz é uma alternativa para priorizarmos as ações em nossa gestão. Sabemos que muitas vezes a decisão é algo compartilhado e que não depende unicamente de uma pessoa, por isso torna-se ainda mais válida esta abordagem quando realizada em grupo.

Consiste em analisar a gravidade, a urgência e a tendência dos problemas enfrentados, sendo:

a. gravidade: o impacto do problema nas operações e pessoas envolvidas no processo;

b. urgência: a brevidade necessária para a resolução do problema; c. tendência: apresentação de melhora ou piora do problema.

Cada problema deve ser ponderado de 1 a 5 em cada critério, tendo como base para ponderação a seguinte tabela:

TABELA 1

Matriz de priorização GUT

\begin{tabular}{c|l|l|l}
\hline Nota & \multicolumn{1}{|c|}{ Gravidade } & \multicolumn{1}{|c|}{ Urgência } & \multicolumn{1}{|c}{ Tendência } \\
\hline 5 & $\begin{array}{l}\text { Extremamente } \\
\text { grave }\end{array}$ & Extremamente urgente & $\begin{array}{l}\text { Se năo for resolvido, piora } \\
\text { imediatamente }\end{array}$ \\
\hline 4 & Muito grave & Muito urgente & Vai piorar em curto prazo \\
\hline 3 & Grave & Urgente & Vai piorar em médio prazo \\
\hline 2 & Pouco grave & Pouco urgente & Vai piorar em longo prazo \\
\hline 1 & Sem gravidade & Sem urgência & Sem tendencia de piorar \\
\hline
\end{tabular}

Após essa ponderação, somam-se na horizontal os valores de cada problema e pelo total eles se hierarquizam. Temos como exemplo:

TABELA 2

Priorização GUT sobre impossibilidade de acesso e uso da informação na biblioteca

\begin{tabular}{|c|c|c|c|c|c|}
\hline $\begin{array}{c}\text { IMPOSSIBILIDADE DE ACESSO E } \\
\text { USO DA INFORMAÇĀO NA } \\
\text { BIBLIOTECA }\end{array}$ & G & $\mathrm{U}$ & $\mathrm{T}$ & Total & $\begin{array}{l}\text { Priori- } \\
\text { zação }\end{array}$ \\
\hline \multicolumn{6}{|l|}{ MATERIAL } \\
\hline \multicolumn{6}{|l|}{ Ausência de livros em braille no acervo } \\
\hline \multicolumn{6}{|l|}{ Falta de rampa de acesso } \\
\hline \multicolumn{6}{|l|}{$\begin{array}{l}\text { Catálogos, sites, bases de dados que não } \\
\text { seguem as normas de acessibilidade }\end{array}$} \\
\hline \multicolumn{6}{|l|}{ Mobiliário inadequado } \\
\hline \multicolumn{6}{|l|}{ Ausência de sinalizaçẫo visual e sonora } \\
\hline \multicolumn{6}{|l|}{ MÉTODO } \\
\hline \multicolumn{6}{|l|}{ Ausência de estudo da comunidade } \\
\hline \multicolumn{6}{|l|}{$\begin{array}{l}\text { Desconsideração com as normas de } \\
\text { acessibilidade }\end{array}$} \\
\hline \multicolumn{6}{|l|}{ Leiaute inadequado } \\
\hline \multicolumn{6}{|l|}{ Falta de planejamento de acessibilidade } \\
\hline \multicolumn{6}{|l|}{ MÃO-DE-OBRA } \\
\hline \multicolumn{6}{|l|}{$\begin{array}{l}\text { Número insuficiente de funcionários para } \\
\text { atender às necessidades da biblioteca }\end{array}$} \\
\hline \multicolumn{6}{|l|}{$\begin{array}{l}\text { Desconhecimento do tema acessibilidade e } \\
\text { pessoas com necessidades educacionais } \\
\text { especiais (PNEEs) }\end{array}$} \\
\hline \multicolumn{6}{|l|}{$\begin{array}{l}\text { Desconhecimento das tecnologias } \\
\text { adaptadas gratuitas }\end{array}$} \\
\hline \multicolumn{6}{|l|}{ Falta de qualificação de pessoal } \\
\hline \multicolumn{6}{|l|}{ Desmotivação } \\
\hline \multicolumn{6}{|l|}{ MÁQUINA } \\
\hline \multicolumn{6}{|l|}{ Ausência de tecnologia acessivel } \\
\hline \multicolumn{6}{|l|}{ Alto custo dos softuares adaptados } \\
\hline \multicolumn{6}{|l|}{ Tecnologia defasada } \\
\hline \multicolumn{6}{|l|}{$\begin{array}{l}\text { Falta de manutenção dos equipamentos } \\
\text { existentes }\end{array}$} \\
\hline Ausência de marketing acessivel & & & & & \\
\hline
\end{tabular}


Neste caso, então, a "acessibilidade" é o problema que seria resolvido primeiramente e seguida a seqüência da Matriz.

\section{Ciclo PDCA}

O ciclo PDCA é uma ferramenta para análise e melhoria de processos e facilmente aplicada em processos de produção e de serviços. É utilizada quando queremos definir, planejar ou implantar um processo.

O ciclo é dividido em quatro fases, uma para cada letra de seu nome que correspondem cada uma a um verbo da língua inglesa, que são to Plan, to Do, to Check e to Act.

O quadro a seguir, extraído do Manual de Ferramentas da Qualidade - Sebrae, explica melhor cada passo do ciclo.

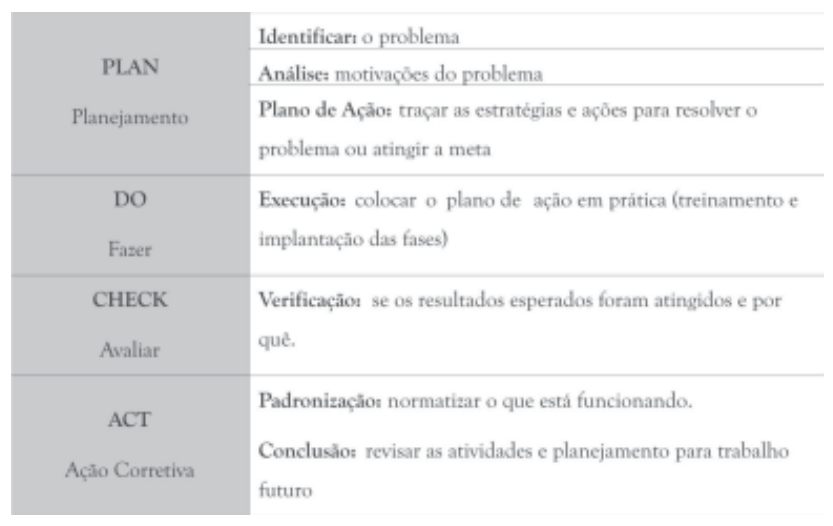

Caso ainda não esteja satisfatório, repetir desde o P novamente.

Esse processo usualmente é apresentado na forma de um círculo, e sua aplicação é chamada de giro do PDCA, como descreve a figura 5 :

FIGURA 5

\section{Ciclo PDCA}

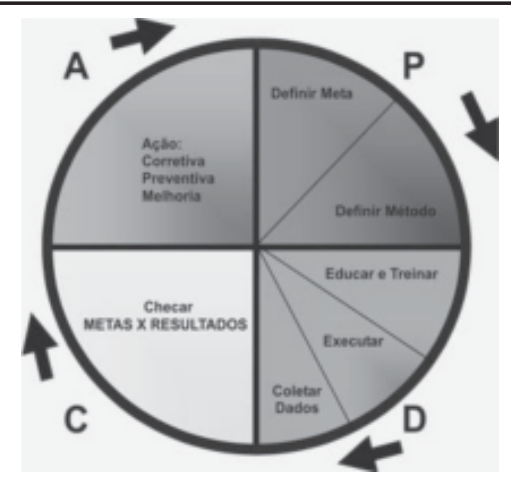

Fonte: http://www.admtoday.com/wp-content/uploads/2008/02/ ciclo-pdca.jpg
Temos então um exemplo simples de aplicação do PDCA.

\section{QUADRO 1}

Exemplo de aplicação do PDCA na visão de gestão em biblioteca escolar e na visão empresarial $\left({ }^{*}\right)$.

\begin{tabular}{|c|c|}
\hline PLAN & $\begin{array}{l}\text { Identificar: aumentar o número de empréstimo de livros } \\
\text { de literatura para os alunos do ensino fundamental de } 5^{\mathrm{a}} \\
\text { a } 8^{\mathrm{a}} \text { série. * (Aumentar as vendas). } \\
\text { Análise: Existem alunos que freqüentavam a biblioteca } \\
\text { até a } \text { 4 }^{\mathrm{a}} \text { série do Ensino Fundamental. Ao chegarem na } 5^{\mathrm{a}} \\
\text { série em diante, freqüentam raramente e/ou não } \\
\text { freqüentam mais. * (Existem zonas não alcançadas pelos } \\
\text { vendedores) }\end{array}$ \\
\hline $\begin{array}{l}\text { Planeja- } \\
\text { mento }\end{array}$ & 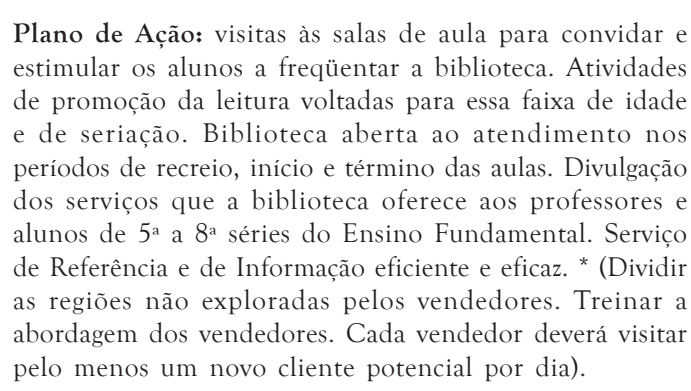 \\
\hline $\begin{array}{l}\text { DO } \\
\text { Fazer }\end{array}$ & $\begin{array}{l}\text { Execução: colocar o plano de ação em prática (treinamento } \\
\text { e implantação das fases) }\end{array}$ \\
\hline $\begin{array}{l}\text { CHECK } \\
\text { Avaliar }\end{array}$ & $\begin{array}{l}\text { Verificação: ações eficazes e resultadas de aumento de } \\
20 \% \text { do empréstimo de livros de literatura para os alunos } \\
\text { de } 5^{\text {a a }} 8^{\text {a }} \text { séries do ensino fundamental no primeiro mês } \\
\text { e aumento progressivo até o final do ano. Aumento do } \\
\text { número de freqüência e acesso e uso dos serviços } \\
\text { oferecidos. * (A partir do } 2^{\circ} \text { mês de ações, estabilizando o } \\
\text { faturamento nos dois meses seguintes) }\end{array}$ \\
\hline $\begin{array}{c}\text { ACT } \\
\text { Ação } \\
\text { corretiva }\end{array}$ & Conclusão: (Não) houve a necessidade de correção. \\
\hline
\end{tabular}

\section{Fluxograma}

O fluxograma é uma tentativa de visualizarmos holisticamente determinada atividade e, por definição, é a representação gráfica das diversas tarefas deste processo.

O fluxograma deve trazer o maior número de informações possível a seu usuário, contudo, para que seja um instrumento objetivo e não fique excessivamente carregado, por vezes é fundido a outras ferramentas. Sua apresentação facilita a identificação de pontos críticos do processo e consegue definir claramente os limites do mesmo.

Para Brassard (1996), apud Vergueiro (2002)², o fluxograma possibilita a identificação de eventuais lapsos, que são uma eventual origem de problemas, e é utilizado

2 BRASSARD, Michael. Qualidade: ferramentas para uma melhoria continua. Rio de Janeiro: Quality Mark, 1996, apud VERGUEIRO, Valdomiro. Qualidade... 
na atividade em que o autor denomina imagineering, na qual as pessoas que detêm maior conhecimento sobre o processo se reúnem para desenhar o fluxograma atual, o fluxograma de como deveria ser feito e, posteriormente, os comparam.

Seu principal objetivo é atuar na identificação de problemas e orientar a tomada de decisão dos gestores, mas também é muito útil para apresentarmos um processo a quem chega novo em uma empresa ou para definirmos um leiaute adequado para determinado setor.

A simbologia utilizada nos fluxogramas é convencionada, mas está sempre sujeita à adaptação para que exista melhor entendimento dos usuários. Existem softwares especializados na elaboração de fluxogramas, mas nos softwares de edição de texto também existe uma gama de símbolos e suas explicações.

Os símbolos mais comuns são os seguintes:

a. operação (retângulo): seu texto sempre tem uma ação, ou seja, tem sempre a presença de um verbo. Caracterizase por indicar uma etapa do processo;

b. decisão (losango): representa um momento do processo onde deve ser tomada alguma decisão. Caracteriza-se sempre por uma pergunta e tem duas saídas, geralmente, uma para o sim e outra para o não;

c. sentido do fluxo (seta): conduz a seqüência de etapas do processo. Devemos procurar, na medida do possível, não cruzar as setas, para não corrermos o risco de embaralhar o leitor;

d. limites (elipse): indica o início e o fim do processo;

e. conector (círculo): liga duas partes de um processo e é muito utilizado na divisão de páginas;

f. preparação (hexágono): determina um procedimento predefinido.
Para utilizarmos o fluxograma, podemos iniciar definindo o processo a ser desenhado, depois criando um macrofluxo do processo para identificarmos as atividades e seus responsáveis e, por fim, desenhar o processo como ele deve ser realizado. Neste ponto teremos então o processo mapeado da maneira como ele deveria ser feito. Comparemos então com a maneira como ele é de fato feito e ajustemos.

Para exemplificarmos a técnica, vemos na figura 6, a seguir, o processo de seleção e aquisição de obras de uma biblioteca proposto por Maciel (2000).

\section{W2H}

Esta ferramenta é conhecida por diversos nomes, mas escolhemos este por ser o mais encontrado na literatura. Consiste em uma maneira de estruturarmos o pensamento de uma forma bem organizada e materializada antes de implantarmos alguma solução no negócio.

O $5 \mathrm{~W}$ do nome correspondem às palavras de origem inglesa What, When, Why, Where e Who, e o $2 \mathrm{H}$, à palavra How e à expressão How Much. Traduzindo: $\mathrm{O}$ quê, Quando, Por quê, Onde, Como, Quem e Quanto.

Ou seja, quando nos depararmos com determinada tarefa, perguntaremo-nos cada uma dessas palavras e escreveremos as respostas. Essa ferramenta ajuda a melhorar a segregação de tarefas dentro de um processo e a ver, de maneira gerencial, como os processos estão de desenvolvendo.

Por exemplo, tentemos descrever um processo simples como a aquisição de acervo através de compra para a biblioteca (quadro 2).

\section{QUADRO 2}

Aplicação do 5W2H sobre aquisição de acervo

\begin{tabular}{|c|c|c|c|c|c|c|}
\hline O quê? & Quando? & Por quê? & Onde? & Como? & Quem? & Quanto? \\
\hline $\begin{array}{c}\text { Aquisição } \\
\text { mediante } \\
\text { compra de } \\
\text { acervo } \\
\text { bibliográfico }\end{array}$ & $\begin{array}{l}\text { Sempre } \\
\text { que tiver } \\
\text { recursos } \\
\text { financeiros } \\
\text { disponiveis }\end{array}$ & $\begin{array}{l}\text { Atualização e } \\
\text { realimentação do } \\
\text { acervo }\end{array}$ & Tesouraria & $\begin{array}{l}\text { Aquisição direta da } \\
\text { editora ou do } \\
\text { distribuidor, com } \\
\text { base em listagem } \\
\text { sugerida pelos } \\
\text { professores, biblioteca } \\
\text { e usuários }\end{array}$ & Bibliotecário & $\begin{array}{l}\text { Atingimento do } \\
\text { crédito } \\
\text { disponivel }\end{array}$ \\
\hline
\end{tabular}


FIGURA 6

Fluxograma acoplado de seleção e aquisição

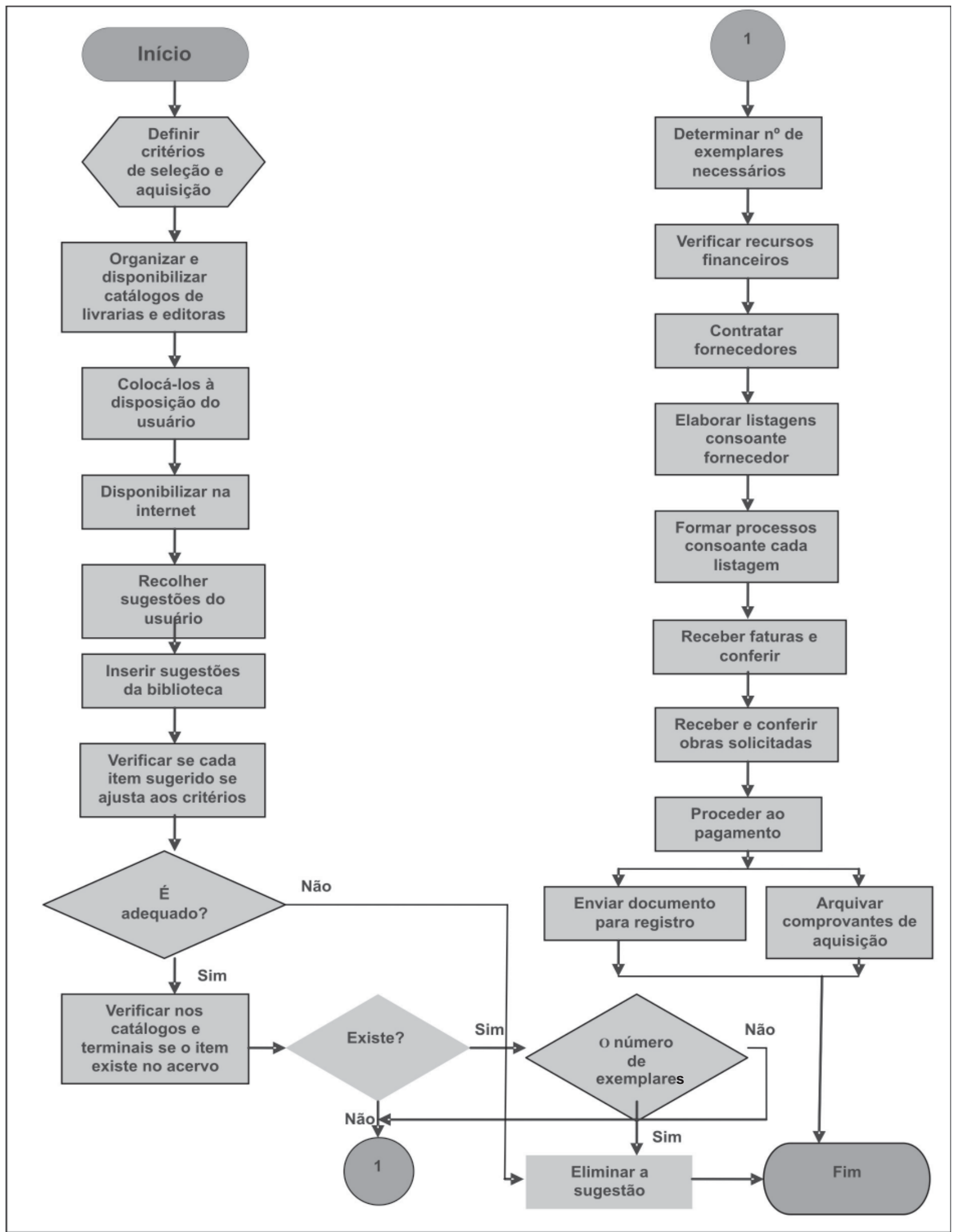


Como vimos então, cada pergunta é respondida de maneira clara e objetiva, mas devemos atentar para que priorizem o seguinte:

- o quê: qual a ação desenvolvida;

- quando: quando será realizada;

- por quê: qual será o resultado esperado da ação;

- onde: onde a ação será desenvolvida;

- como: como será implementada, precisa descrever passos;

- quem: quem será o responsável pela implantação;

- quanto: quanto será gasto.

Utilizando esta ferramenta, podemos então planificar nosso processo e analisá-lo de maneira compartida. Uma abordagem muito interessante é a da junção desta ferramenta com o fluxograma na coluna do "o quê" e ainda do Ciclo PDCA, mas trataremos dela mais adiante.

\section{APLICAC̣ÃO \\ PRÁTICA (FLUXOGRAMA, PDCA e 5W2H)}

O bibliotecário que atua em biblioteca escolar de instituições educacionais públicas ou privadas deve priorizar o atendimento de qualidade aos seus alunos, professores, funcionários e comunidade escolar, mediante padrões de qualidade em serviços realizados e oferecidos atendendo às prioridades e necessidades dos seus usuários. Além disso, os bibliotecários devem munirse de instrumentos que possibilitem a percepção dos seus usuários quanto aos serviços recebidos com benefícios para todos os envolvidos, tanto para os profissionais quanto para os usuários.

Com o intuito de auxiliar e possibilitar uma análise mais completa e detalhada dos serviços de qualidade oferecidos pela biblioteca escolar, apresentamos uma aplicação de três ferramentas (Fluxograma, PDCA e 5W2H), que pode servir de mapa de utilização para que os usuários da

\section{FIGURA 7}

PDCA x Fluxograma x 5W2H

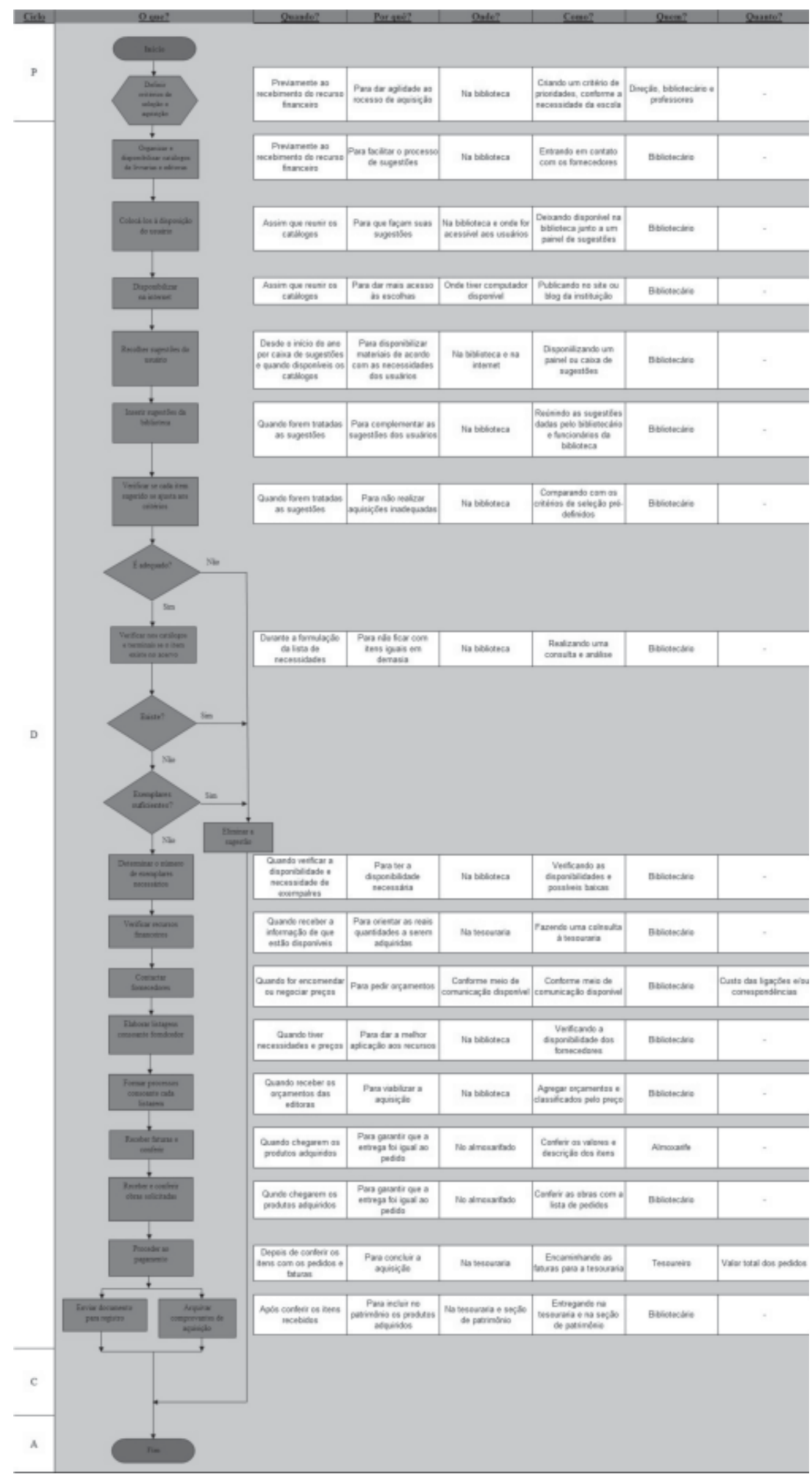

biblioteca escolar tenham condições de participar da gestão de qualidade tomando conhecimento e compreendendo o processo em questão: 


\section{CONSIDERAC̣ÕES FINAIS}

A gestão da biblioteca escolar é um processo primordial na oferta e no desenvolvimento de qualidade em serviços de informação em relação a metodologias, enfoques e aplicação de ferramentas que podem auxiliar os bibliotecários a oferecer a informação adequada, no momento certo, pois, como afirmava Ranganathan em uma de suas leis, a biblioteca é um organismo em crescimento.

A sociedade da informação e do conhecimento preconiza a integração, reduzindo distâncias e aumentando o nível de informação, a igualdade no acesso e no uso da informação, e a aprendizagem possibilita a superação de desigualdades e de exclusão. Por isso, a escola, aonde acorrem milhares de crianças, de adolescentes e de adultos, transforma-se no espaço que propicia a convivência, o compartilhamento, a autonomia e a aprendizagem, ocupando espaços físicos de salas de aulas, de laboratórios e de bibliotecas escolares. Nestas, o bibliotecário que busca a atualização e a especialização para sua competência informacional propiciará aos seus usuários espaços de convivência de aptidões intelectuais e cognitivas, de cidadania e de acesso à informação para todos, através da qualidade dos serviços prestados, avaliados em programas e ferramentas de qualidade em serviços de informação para todos.

Artigo submetido em 22/10/2008 e aceito em 22/12/2008

\section{REFERENNCIAS}

BERTALANFFY, Ludwig Von. Teoria geral dos sistemas. São Paulo: Vozes, 1975.

INTERNATIONAL FEDERATION OF LIBRARY ASSOCIATIONS AND INSTITUTIONS. School library manifesto. Disponivel em: <http:/ /www.ifla.org/VII/s11/pubs/schoolmanif.htm>. Acesso em: 2008.

MACEDO, Neusa Dias de (Org.). Biblioteca escolar brasileira em debate: da memória profissional a um fórum virtual. São Paulo: CRB 8a Região, 2005.

MACIEL, Alba Costa; MENDONÇA, Marília Alvarenga Rocha. Bibliotecas como Organizações. Rio de Janeiro: Interciência, 2000.

SEBRAE. Manual de ferramentas da qualidade. 2005. Disponível em: < h t t p :// r e mon a to.pro.br/documents/ ManualDeFerramentasDaQualidade-Sebrae.pdf>. Acesso em: 2008.

VERGUEIRO, Waldomiro. Qualidade em serviços de informação. São Paulo: Arte \& Ciência, 2002. 